\title{
Senna Tablet Increases Radiation Dose Excreted at Discharge Time in Patients Who Underwent lodine Therapy
}

Farshid Gheisari

Shiraz University of Medical Sciences

Mohammad Atefi

Shiraz University of Medical Sciences

Alireza Mehdizadeh

Shiraz University of Medical Sciences

Ahmad Mohammadi

Shiraz University of Medical Sciences

\section{Zahra Shabani}

Shiraz University of Medical Sciences

Ali Shahabinezhad

Shiraz University of Medical Sciences

Ehsan Amiri-Ardekani ( $\nabla$ ehsanamiri@sums.ac.ir)

Shiraz University of Medical Sciences https://orcid.org/0000-0001-8948-9153

\section{Research Article}

Keywords: Thyroid cancer, Senna, Thyroid nodule, Radiation dose at discharge, Senna alexandrina Mill

Posted Date: August 17th, 2021

DOl: https://doi.org/10.21203/rs.3.rs-794199/v1

License: (c) (i) This work is licensed under a Creative Commons Attribution 4.0 International License. Read Full License 


\section{Abstract}

Introduction: Thyroid cancer is a malignancy accounting for less than $1 \%$ of human malignancies. This study aim was to investigate the effect of Senna tablets (C-Lax ${ }^{\circledR}$ ) in increasing the dose of radiation excreted in patients who underwent iodine therapy in the iodine treatment center of Namazi Hospital of Shiraz University of Medical Sciences at discharge time.

Methods: In this study, 180 female patients aged 30-50 years old with BMI ranges from 22 to 26 and no history of gastrointestinal diseases, especially gastrointestinal ulcers, constipation, and known intestinal diseases, were included in our study into 6 groups of 30 patients. The first three groups received 100, 150, and $200 \mathrm{mCi}$ radiation respectively, and did not receive C-lax tablets. The second three groups received 100,150 , and $200 \mathrm{mCi}$ radiation respectively, and additionally, received 2 C-lax tablets of Dineh Iran Pvt. Ltd.

Results: In all 3 doses studied, more than $50 \%$ of reduction in radiation dose at discharge was seen. There is a statistically significant difference between the different doses of iodine intake in each of the two groups. Results show that there is a statistically significant difference between groups with consumption and without consumption of C-Lax tablets in all three doses paired groups

Discussion and Conclusion: The radiation dose of patients at discharge time has an important effect on both patients and their families' health and thereby it should be taken into consideration. C-lax tablets can significantly reduce the radiation dose of patients at their discharge. This can result in better compliance of patients and decreased expenses for the health system and patients

\section{Introduction}

\section{Radiation in thyroid cancer}

In 2020, new cases of thyroid cancer are estimated to be 52,890 patients with a $2.9 \%$ death rate ("SEER Cancer Stat Facts: Thyroid Cancer. National Cancer Institute," 2021). Thyroid cancer is more common in young and middle-aged women. Its one of the most common cancers in humans and papillary and follicular types are its most prevalent types (Petrich et al., 2001).

Surgery, radiation therapy, and chemotherapy are the main treatments for thyroid carcinoma (Petrich et al., 2001). Radiation with ionizing rays has negative impacts on biological tissues, and in certain doses, quantities and intensities can cause irreversible tissue damages, cancer, and even death (Mehrosadat et al., 2015). Despite its negative results, radioactive iodine has been used to treat benign and malignant thyroid cancer since 1940 (Siegel, Naishadham, \& Jemal, 2012). Thyroid cancer can be surgically removed after diagnosis and since its remaining cells absorb radioactive iodine, they are eliminated by radioactive iodine after surgery. Beta particles radiating from radioactive iodine destroy the follicular cells and gradually lead to a decrease in remaining thyroid volume and control of thyrotoxicosis. As a result, iodine therapy is usually performed to destroy the remaining cancerous cells of the thyroid or probable 
cancer metastasis. An important feature of thyroid cancer cells that differs from other cancer cells is that they considerably absorb iodine, and as a result, the iodine is concentrated in the thyroid remaining cells, which results in cell death. It must be said that most healthy cells of the human body survive as they do not absorb iodine (Petrich et al., 2001). Radiation therapy is performed with radioactive iodine or by external radiation. After thyroidectomy, it must be ensured that no cancer cells are left. In contrast to most cancers, in which chemotherapy is used for the elimination of remaining cells, chemotherapy is not effective for thyroid metastases and thereby these patients are treated with radioactive iodine. It is obvious that iodine therapy maximizes the therapeutic effect of subsequent treatments and it also reduces the recurrence and mortality rates of thyroid carcinoma and even can prevent distant metastasis (Haugen et al., 2016). When radioactive iodine is absorbed by thyroid tissue, its therapeutic effects begin; because of high-energy beta ray emission and eventually will result in cell death within a few weeks (La Perle et al., 2013).

lodine 131 is one of the radionuclides which accumulate in the thyroid gland. In patients who underwent thyroidectomy, as the thyroid gland has been removed, iodine 131 is distributed to other organs of the body. lodine 131 or radioactive iodine is a radiant isotope of iodine that has a half-life of 8 days. This isotope is mainly produced artificially and it is often used in imaging procedures or the treatment of hyperthyroidism, thyroid cancer, and some other cancers. In imaging studies such as thyroid scans, the patient receives a small dose of radioactive iodine that accumulates in thyroid tissue or certain types of tumors, and sites of radioactive iodine accumulation can be detected using a scanner. It has been reported that locations, where more radioactive iodine has accumulated, are overactive sites (hot thyroid nodules) (Aschebrook-Kilfoy et al., 2013; Schneider \& Chen, 2013).

\section{Senna}

Herbal Medicine has been used widely in traditional and ethnic medicine(Ardekani, Askari, \& Mohagheghzadeh, 2020). In recent years most of researchers in field of herbal medicine have put an emphasis on clinical trials of such products(Amiri-Ardekani \& Tehrany, 2021; Bhosale \& Banerjee, 2020). One of these valuable herbs is Senna. Senna (Senna alexandrina Mill.) from Genus Senna and Leguminosae family("The Plant List," 2021) is a valuable plant due to its laxative(Vilanova-Sanchez et al., 2018; Wang et al., 2020), anti-obesity, anti diabetic(Yuniarto, Sukandar, Fidrianny, Setiawan, \& Ketut, 2018), and hepatoprotective(Wang et al., 2020) activity. S.alexandrina is one of the most popular and important species of this genus, which is mentioned in the world's renowned pharmacopeias(Ahmad, Hassan, Abbasi, \& Rehman, 2018). Many species of the Senna genus are sources of tannins, and thereby they have also high economic and therapetic value (Maia, Trevisan, Silva, Breuer, \& Owen, 2017; Oladeji, Adelowo, \& Oluyori, 2021).

sennosides are among the major ingredients of Senna. These glycosides (especially A and B sennosides and their active metabolite, rhein-anthrone) are responsible for Senna leaves and fruit laxative activity. Two mechanisms have been proposed for Senna laxative activity. The first mechanism is electrolyte and water absorption from the large intestine that results in higher volume and pressure in the large intestine and eventually increases colon motility. The second mechanism is active chloride secretion mediated by 
stimulation of endogenous prostaglandin E2 that results in increased water and electrolyte content of the intestine and eventually increased colon motility(Ramchander \& Middha, 2017; Zhao et al., 2016).

Due to the safety and therapeutic aspects of S.alexandrina from one hand and the need to increase radiation dose excreted at discharge time in patients who underwent iodine therapy for the first time in the world in this study we evaluate the role of Senna tablets (commercially known as C-Lax $®$ ) in increasing radiation dose excreted at discharge time in patients who underwent iodine therapy.

\section{Material And Methods}

This clinicl trial study was performed in the lodine Therapy Center of Namazi hospital from 2019 fall to winter of 2020.

Inclusion criteria were female patients aged 30-50 years with BMI range from 22 to 26 . The exclusion criteria were history of gastrointestinal disease, especially gastrointestinal ulcers, constipation. finally, based on inclusion and exclusion criteria 180 female patients were included in our study.

In this study, patients of the same sex as females in an age range with close body mass index and no GI problems were included in the study. Thus, for the prescribed dose, the patient was divided into two groups. used C-Lax Tablets as a laxative supplement and the group did not use them. In other words, the choices were not random and were based on the said characteristics. Participants were divided into 6 groups with Excel®.

The first 30 patients received $100 \mathrm{mCi}$ iodine radiation and did not take C-Lax® tablets. The second group of patients received a dose of $150 \mathrm{mCi}$ radiation and did not take C-Lax® tablets. The third group included 30 patients who received a dose of $200 \mathrm{mCi}$ radiation and did not take C-Lax $\circledast$ tablets. The next 3 groups also received $100 \mathrm{mCi}, 150 \mathrm{mCi}$, and $200 \mathrm{mCi}$ radiation dose, respectively. But, these 3 groups were prescribed with 2 C-Lax® tablets made by Dineh Iran Pvt. Ltd. 24 hours before hospitalization and also every night during their hospitalization period. All patients also were asked to drink a enough water.

The groups were compared in pairs based on the amount of radioactive iodine dose received. The criterion for comparison was the radiation dose at discharge time based on the micro Sieverts per hour at a distance of 1 meter.

According to the non-normal distribution of iodine radiation in different doses, the nonparametric test of Kruskal-Wallis was used. Statistical analysis were done using SPSS Ver 22.

Ethical protocol of this study was approved by Ethics Committee of Shiraz University of Medical Sciences under IR.SUMS.MED.REC.1399.367 code.

\section{Results}


Table 2

comparison of the mean difference of iodine doses in each paired groups

\begin{tabular}{|c|c|c|c|}
\hline Significance level & Mean \pm Standard deviation & variable & \\
\hline \multirow[t]{2}{*}{$<0.001^{*}$} & $38.81 \pm 5.31$ & Without C-Lax® & \multirow[t]{2}{*}{$100 \mathrm{mCi}$} \\
\hline & $13.2 \pm 0.98$ & With C-Lax® & \\
\hline \multirow[t]{2}{*}{$<0.001^{*}$} & $44.00 \pm 95.3$ & Without C-Lax® & \multirow[t]{2}{*}{$150 \mathrm{mCi}$} \\
\hline & $18.17 \pm 1.25$ & With C-Lax® & \\
\hline \multirow[t]{2}{*}{$<0.001^{*}$} & $40.83 \pm 9.64$ & Without C-Lax® & \multirow[t]{2}{*}{$200 \mathrm{mCi}$} \\
\hline & $20.30 \pm 1.51$ & With C-Lax® & \\
\hline
\end{tabular}

As shown in Figs. 1 and 2, the amount of radioactive material excreted increased in patients who took the C Lax ${ }^{\circledR}$ tablets.

\section{Discussion}

Thyroid cancer is one of the most common malignancies in humans and is more prevalent in young and middle-aged women. The most common types of thyroid cancer are papillary and follicular types, respectively. Treatment of thyroid cancer is mainly surgical removal and since thyroid remaining cells absorb radioactive iodine, they can be eradicated by radioactive iodine after surgery. Radioactive iodine destroys the thyroid follicular cells and can control thyrotoxicosis. Thereby, iodine therapy is often done to destroy the remaining cells of the thyroid and even its malignant metastasis. A key feature of thyroid cells is that they markedly absorb iodine, and thereby, the iodine is absorbed by the remaining cells of the thyroid and will eliminate them, and also it is noteworthy that other types of human cells almost do not hurt as they do not absorb iodine(Lee \& Park, 2010).

Shaheen Dewji et al. have made some important recommendations on the radiation dosage of iodine in patients admitted for iodine therapy in the United States and also patients' condition, staff conditions, condition of physicians exposed to the patients, and most importantly the radiation protection conditions of the patient's companions during and after iodine therapy in 2017. Since patients should be discharged after 24 to 72 hours of quarantine in the iodine therapy ward, the standard and optimal radiation dose of patients should be less than 70 micro Sieverts per hour at a distance of one meter (Dewji \& Hertel, 2017). Report number 63 of the Atomic Energy Organization (IAEA) on the discharge of iodine therapy patients, has stated that the most optimal dose at a distance of 1 meter is less than 70 micro Sieverts per hour, based on a comparison of the standards of Germany, Sweden, Finland and Australia (Fard-Esfahani et al., 2015).

Patients are generally admitted in the nuclear medicine wards between 24 and 72 hours, with an average of 48 hours. The radiation dose of the patients at discharge highly depends on the nutrition and also 
health condition of the patients' urinary and gastrointestinal system. The aim of this study was the evaluation of laxatives especially Senna herbal medicine on the increase of peristaltic movements of the intestine and intestinal emptying and subsequently, increase in the excretion of radioactive materials. This study showed that the radiation dose of patients at discharge time has an important effect on both patients and their families' health and thereby it should be taken into consideration. C-lax tablets can significantly reduce the radiation dose of patients at their discharge. This can result in better compliance of patients and decreased expenses for the health system and patients It must be said that since this study was conducted for the first time in the world, there was no similar study for comparison.

\section{Conclusion}

Our study shows statistically significant evidence in favor of using C-Lax tablets, which indicates the effect of laxatives in reducing the patient's radiation dose during discharge. This result can facilitate this medical procedure and decrease expenses for both the health care system and patients.

\section{Declarations}

\section{Acknowledgments}

Appreciation and gratitude for the financial and spiritual support of Shiraz University of Medical Sciences Vice Chancellor for Research and also Personnel of the Nuclear Medicine lodine Treatment Department of Namazi Hospital, Shiraz University of Medical Sciences.

This article is an extract from the dissertation by A M, a medical student at Shiraz University of Medical Sciences.

\section{Conflict of interest}

The authors have no conflict of interest.

\section{Funding}

We thank Shiraz University of Medical Sciences for financial supports.

\section{References}

1. Ahmad, S., Hassan, A., Abbasi, W. M., \& Rehman, T. (2018). Phytochemistry and pharmacological potential of Cassia absus-a review. Journal of Pharmacy and Pharmacology, 70(1), 27-41.

2. Amiri-Ardekani, E., \& Tehrany, A. (2021). Allium sativum L.(Garlic) Role in Osteoarthritis: A Systematic Review of Clinical Trials. Biointerface Research in Applied Chemistry, 4(11).

3. Ardekani, E. A., Askari, H., \& Mohagheghzadeh, A. (2020). Memorial functional foods: a new concept from Bavi tribe. Journal of Ethnic Foods, 7(1), 1-10. 
4. Aschebrook-Kilfoy, B., Schechter, R. B., Shih, Y. C., Kaplan, E. L., Chiu, B. C., Angelos, P., \& Grogan, R. H. (2013). The clinical and economic burden of a sustained increase in thyroid cancer incidence. Cancer Epidemiol Biomarkers Prev, 22(7), 1252-1259. doi:10.1158/1055-9965.epi-13-0242

5. Bhosale, V. V., \& Banerjee, D. (2020). Scientific validation of herbal medicine Herbal Medicine in India (pp. 573-579): Springer.

6. Dewji, S., \& Hertel, N. (2017). Patient release after radioiodine therapy patient release after radioiodine therapy a review of the technical literature, dose calculations, and recommendations.

7. Fard-Esfahani, A., Fallahi, B., Karimi, M., Beiki, D., Saghari, M., Emami-Ardekani, A., . . Eftekhari, M. (2015). Changes in salivary gland function following radioiodine therapy of thyroid diseases: $A$ comparison of high-dose therapy for thyroid cancer and low-dose therapy for benign thyroid disease. Iranian Journal of Nuclear Medicine, 23, 1-7.

8. Haugen, B. R., Alexander, E. K., Bible, K. C., Doherty, G. M., Mandel, S. J., Nikiforov, Y. E., .. . Wartofsky, L. (2016). 2015 American Thyroid Association Management Guidelines for Adult Patients with Thyroid Nodules and Differentiated Thyroid Cancer: The American Thyroid Association Guidelines Task Force on Thyroid Nodules and Differentiated Thyroid Cancer. Thyroid, 26(1), 1-133. doi:10.1089/thy.2015.0020

9. La Perle, K. M., Kim, D. C., Hall, N. C., Bobbey, A., Shen, D. H., Nagy, R. S., . . Jhiang, S. M. (2013). Modulation of sodium/iodide symporter expression in the salivary gland. Thyroid, 23(8), 1029-1036. doi:10.1089/thy.2012.0571

10. Lee, J. H., \& Park, S. G. (2010). Estimation of the Release Time from Isolation for Patients with Differentiated Thyroid Cancer Treated with High-dose 1-131. Nuclear medicine and molecular imaging, 44(4), 241-245. doi:10.1007/s13139-010-0041-0

11. Maia, I., Trevisan, M. T. S., Silva, M., Breuer, A., \& Owen, R. (2017). Content of total phenolic compounds, flavonoids and tannins in methanol extracts of the genus Senna Mill. from the northeast of Brazil and evaluation of antioxidant capacity. J Pharmacogn Phytochem, 6(5), 13211325.

12. Mehrosadat, A., Mohammad Ali, O., Kourosh, B., Motahareh, M., Fatemeh, E., Ahmad, M., .. . Mohammad, A. (2015). Evaluation the Synergistic Effect of High Dose Radiation of Radioiodine on the Immune System Suppressed By Cyclosporine. American Journal of Immunology, 11(3). doi:10.3844/ajisp.2015.85.91

13. Oladeji, O. S., Adelowo, F. E., \& Oluyori, A. P. (2021). The genus Senna (Fabaceae): A review on its traditional uses, botany, phytochemistry, pharmacology and toxicology. South African Journal of Botany, 138, 1-32.

14. Petrich, T., Widjaja, A., Musholt, T. J., Hofmann, M., Brunkhorst, T., Ehrenheim, C., . . Knapp, W. H. (2001). Outcome after radioiodine therapy in 107 patients with differentiated thyroid carcinoma and initial bone metastases: side-effects and influence of age. Eur J Nucl Med, 28(2), 203-208. doi:10.1007/s002590000420

15. The Plant List. (2021). 
16. Ramchander, J. P., \& Middha, A. (2017). Recent advances on Senna as a laxative: A comprehensive review. J Pharmacogn Phytochem, 6(2), 349-353.

17. Schneider, D. F., \& Chen, H. (2013). New developments in the diagnosis and treatment of thyroid cancer. CA Cancer J Clin, 63(6), 374-394. doi:10.3322/caac.21195

18. SEER Cancer Stat Facts: Thyroid Cancer. National Cancer Institute. (2021). Retrieved from https://seer.cancer.gov/statfacts/html/thyro.html [Accesed date: February 4, 2021]

19. Siegel, R., Naishadham, D., \& Jemal, A. (2012). Cancer statistics, 2012. CA: A Cancer Journal for Clinicians, 62(1), 10-29. doi:https://doi.org/10.3322/caac.20138

20. Vilanova-Sanchez, A., Gasior, A. C., Toocheck, N., Weaver, L., Wood, R. J., Reck, C. A., . . Jaggers, J. (2018). Are Senna based laxatives safe when used as long term treatment for constipation in children? Journal of pediatric surgery, 53(4), 722-727.

21. Wang, X., Wang, T., Pan, T., Huang, M., Ren, W., Xu, G., . . Moneim, A. E. A. (2020). Senna alexandrina extract supplementation reverses hepatic oxidative, inflammatory, and apoptotic effects of cadmium chloride administration in rats. Environmental Science and Pollution Research, 27(6), 5981-5992.

22. Yuniarto, A., Sukandar, E. Y., Fidrianny, I., Setiawan, F., \& Ketut, I. (2018). Antiobesity, Antidiabetic and Antioxidant Activities of Senna (Senna alexandrina Mill.) and Pomegranate (Punica granatum L.) Leaves Extracts and Its Fractions. International Journal of Pharmaceutical and Phytopharmacological Research (elJPPR), 8(3), 18-24.

23. Zhao, Y., Zhao, K., Jiang, K., Tao, S., Li, Y., Chen, W., . . Zhang, K. X. (2016). A Review of Flavonoids from Cassia Species and their Biological Activity. Curr Pharm Biotechnol, 17(13), 1134-1146. doi:10.2174/1389201017666160819151153

\section{Figures}




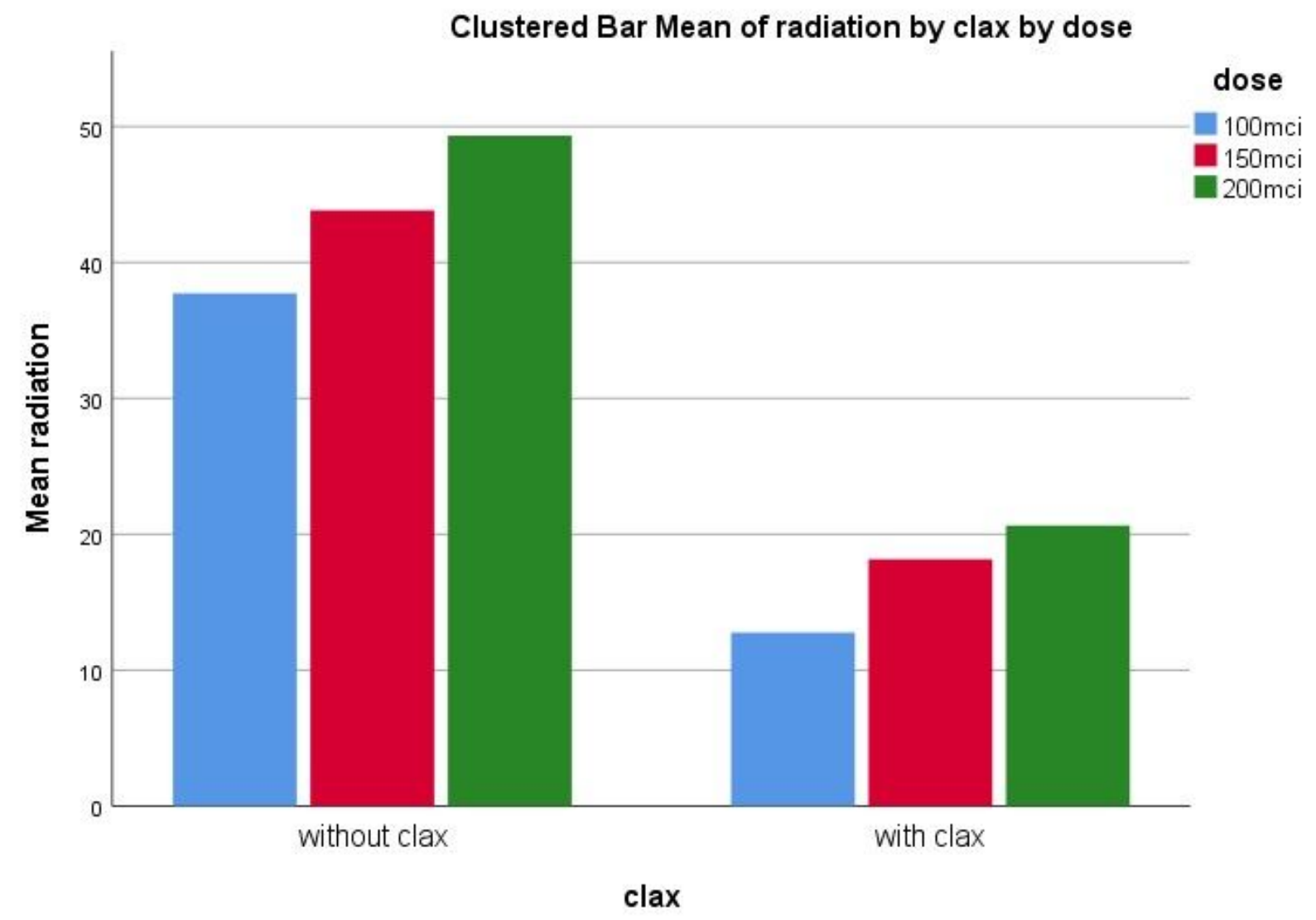

Figure 1

Mean comparison between groups 


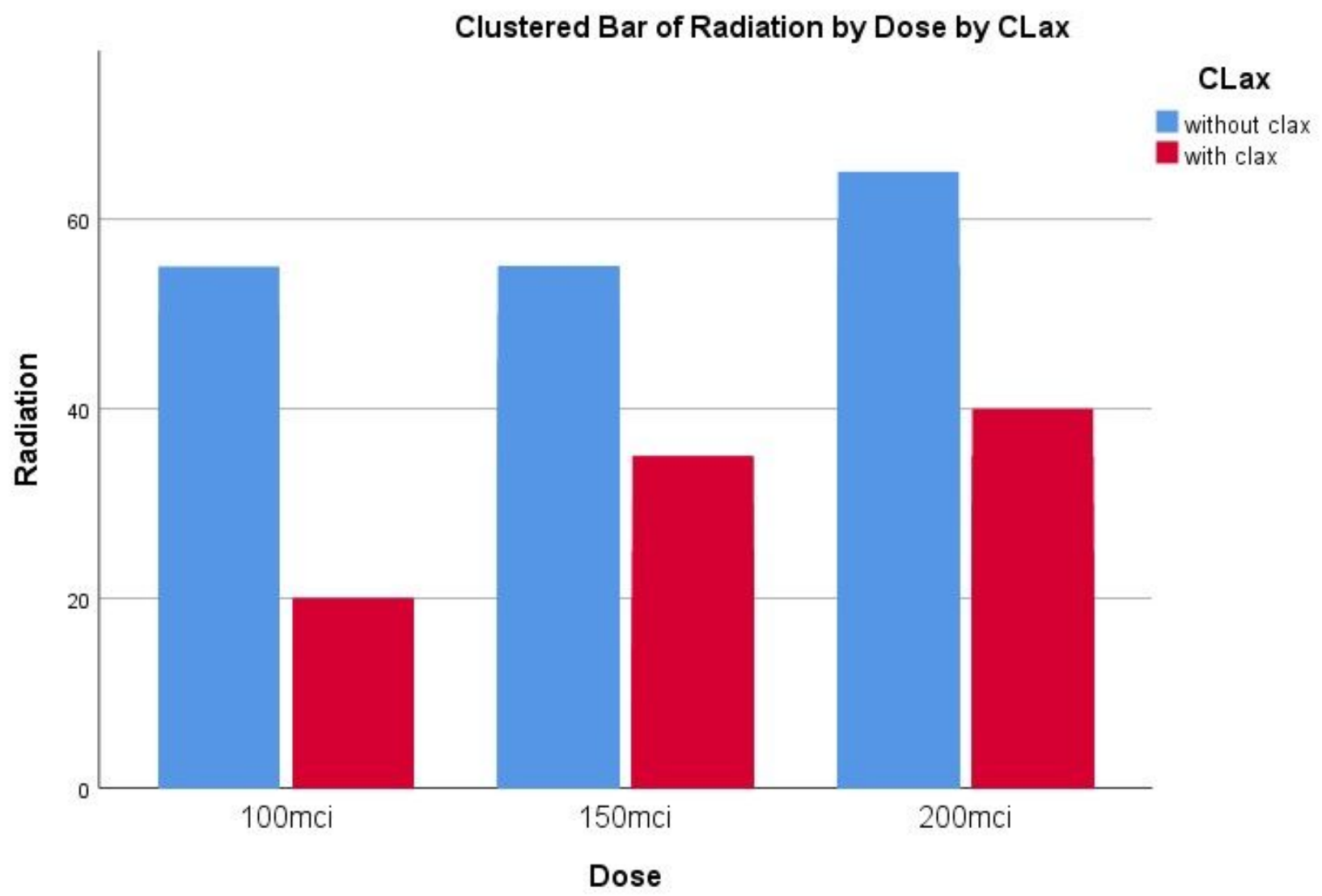

Figure 2

Radiation in each studied group 